\title{
Re: Severe Leptospirosis- a case series and review
}

Editor- I read with interest the paper on severe leptospirosis by Habaragamuwa and Piyasiri ${ }^{1}$. Leptospirosis is a major public health threat to Sri Lanka. Sri Lanka is experiencing a sustained outbreak of Leptospirosis since $2008^{2}$. Despite having a major burden, scientific evidence on leptospirosis epidemiology, clinical disease and manifestations are scarce in Sri Lanka. The paper by Habaragamuwa et al provided a detailed description of severe cases.

Leptospirosis disease diagnosis is often hampered by lack of point of care diagnostic tests. Ambiguity of clinical disease prohibits accurate clinical diagnosis of this disease. Repeated studies have shown that this condition could be mimicked by a range of tropical diseases, including Dengue ${ }^{3}$ and Hanta virus ${ }^{4}$ infections. In our study done during the 2008 outbreak, we showed that the sensitivity and specificity of clinical diagnosis of leptospirosis in Kegalle, Matale and Kandy was less than $60 \%{ }^{5}$. Despite the fact that the paper by Habaragamuwa et al is providing vital information, use of the data presented in the paper as scientific evidence is questionable due to lack of standard diagnosis. This issue of diagnostic dilemma was one major point of discussion during the WHO Leptospirosis Epidemiology Reference Group (LERG) meeting, and the expert group decided diagnosis could be either presumptive or confirmed $^{6}$. For presumptive diagnosis, clinical leptospirosis supported by a single sample serology test is needed, whereas for confirmation, antigen based diagnosis of paired sample serology test results are needed. Clinical symptoms alone would not be considered even for presumptive diagnosis. However, those could be treated as"possible" cases of leptospirosis.
The data presented would be more usable in scientific literature if the diagnostic criteria were clearly defined and patients were classified as "possible" or "probable (presumptive)" cases. Use of standard definitions and criteria for diagnosis will always allow comparison of cases across studies and helpful in disease burden assessment.

Suneth B Agampodi

Department of Community Medicine, Faculty of Medicine and Allied Sciences, Rajarata University of Sri Lanka and, Division of Infectious Diseases, Department of Medicine, School of Medicine, University of California, San Diego

1. Habaragamuwa BWP, Piyasiri G. Severe Leptospirosis- A case series and review. Sri Lankan Journal of Anaesthesiology. 2011;19(1):22-25.

2. Agampodi S, Peacock SJ, Thevanesam V. The potential emergence of leptospirosis in Sri Lanka. Lancet Infect Dis. Sep 2009;9(9):524-526.

3. Ellis T, Imrie A, Katz AR, Effler PV. Underrecognition of Leptospirosis During a Dengue Fever Outbreak in Hawaii, 20012002. Vector Borne Zoonotic Disease. Apr 30 2008.

4. Santos VM, Rocha de Sa DA, Turra TZ, Ferreira Borges NM, Nascimento UM, Damasceno EA. Hantavirus pulmonary syndrome in Brasilia periphery: a diagnostic challenge. Journal of Infections in Developing countries. 2009;3(8):639-643.

5. Agampodi S. Epidemiology of Leptospirosis among patients admitted to selected tertiary care hospitals in three endemic districts in Sri Lanka, during the 2008 epidemic. Colombo: Community Medicine, University of Colombo; 2010.

6. World Health Organization. Report of the first meeting of leptospirosis burden epidemiology reference group. Geneva: World Health Organization 2010. 


\section{Reply from the authors}

Editor,

We are grateful to Dr Suneth B Agampodi for highlighting the difficulty in diagnosing leptospirosis on clinical diagnostic criteria alone. The case series we have presented indicates the main organ system involved at the time of ICU admission and during the course of ICU stay. It also indicates the common organ systems involved in the diseased patients though data is inadequate to make any definitive conclusions. These findings may help early identification of patients with severe leptospirosis in order to provide early critical care treatment. We hope that the information can be used to design future studies on bad prognostic features of leptospirosis or to look for an early warning scoring system in leptospirosis. We agree that the number of cases in the series would be inadequate to draw any definitive conclusions and that the diagnosis of leptospirosis was not definitive.

BWP Habaragamuwa, G Piyasiri

$* * * * * * * * * * * * * * * * * * * * * * * * * * * * * * * * * * * * * * * * * * * * * * * * * * * * * * * * * * * * * * * * * * * * * *$

\section{THE COLLEGE OF ANAESTHESIOLOGISTS OF SRI LANKA}

\section{B S PERERA ORATION}

Applications are hereby called for the "B. S. Perera Oration", to be held on the $2^{\text {nd }}$ February 2013 at the $29^{\text {th }}$ Annual Scientific Sessions of the College.

\section{Terms and Conditions for the Oration.}

1. Five copies of the entire oration should be sent before $31^{\text {st }}$ October 2012 to The Secretary, College of Anaesthesiologists of Sri Lanka and there should not be any substantial alteration in the text when the lecture is finally delivered.

2. The lectureship is open to all members of the College of Anaesthesiologists.

3. Five copies of a brief resume of the salient points of the paper should also be submitted indicating any contribution to further advances in knowledge of the subject.

4. The lecture should preferably not exceed 45 minutes.

5. A committee of five will be nominated by the council to scrutinize papers submitted and to select a suitable candidate. This committee of five shall award the lectureship.

6. The lecture should be related to anaesthesia and intensive care and should be based on the original work of the lecturer.

7. In the event of the committee being unable to select a lecturer from the applicants, they may invite a lecturer of international repute to deliver the lecture ship.

8. The honorium may be in the form of a gold medal.

9. Press should not be invited and photographs and accounts of the lecture should not be published in the Newspapers, without the permission of the College Council.

10. Copyright of the oration belongs to the College of Anaesthesiologists of Sri Lanka. 